\title{
Gate Location and Injection Analysis of a Spur Gear
}

\author{
Wafiuddin Md Ghazali ${ }^{1}$, Daing Mohamad Nafiz Daing Idris ${ }^{1,}$, , Azizul Helmi Sofian ${ }^{2}$ Januar \\ Parlaungan Siregar ${ }^{1}$, and Mohamad Firdaus Basrawi ${ }^{1}$ \\ ${ }^{1}$ Faculty of Mechanical Engineering, Universiti Malaysia Pahang, 26600, Pekan, Pahang, Malaysia. \\ ${ }^{2}$ Faculty of Chemical \& Natural Resources Engineering, Universiti Malaysia Pahang, 26300 \\ Gambang, Kuantan, Pahang, Malaysia
}

\begin{abstract}
Injection moulding process is one of the common processes to produce plastic parts from simple to complicated parts. This paper focuses on the injection process analysis of a 25 tooth spur gear. Three runner system are proposed for the gear and each system will be analysed using Autodesk Simulation Moldflow Advisor. The most suitable design will then be chosen based on the results obtained from the simulation. The design undergoes cooling quality, sink mark, fill + pack, and warp analysis. Based on these analyses, Design 1 gave the better results compared to Design 2 and 3. From there, Design 1 runner system is chosen for the injection moulding mould which will be fabricated later in the research.
\end{abstract}

\section{Introduction}

Polymers can be processed into parts using several methods such as injection moulding, compression moulding, thermoforming and blow moulding [1]. Depending on the design of the part, some methods are suitable while some are not. For a mass production process of a plastic part, injection moulding is the preferred method. Its high initial cost is complemented by the low running cost in the long term.

To produce a mould for a part, several facts must be taken into accounts such as the part size, type of mould, material properties [2,3] and the expected outcome of the product. The parameters of injection process should also be considered in producing a plastic part. An injection process with different pressure and velocities which were later compared to injection moulding analysis results [4]. E. Hakimian and A. B. Sulong [5] studied the effect of injection moulding parameters such as packing time, cooling temperature, moulding and melting temperatures and the packing and injection pressure. The warpage and shrinkage effect of these parameters on several different fibre glass reinforced material were analysed using Taguchi method. The results obtained shows that polyphenylene-ether/polystyrene (PPE/PS) had the highest improvement in shrinkage analysis, and polycarbonate/acrylonitrile-butadiene-styrene (PC/ABS) had the greatest improvement in the warpage analysis. B. Sha et al. [6] focuses on processing parameters which are barrel temperature, mould temperature and injection speed and distance between the cavities. It was

\footnotetext{
*Corresponding author: daingnafiz@ump.edu.my
} 
found out that increasing the barrel temperature, mould temperature and injection speed improves the polymer melting and filling process, but it depends on the polymer material used and can be adverse in certain conditions. Surface quality and edge definition is also affected when the processing parameters are manipulated.

W. A. W. A. Rahman et al. [7] carried out analysis on flowing, packing, cooling and costing of injection moulding process for a window frame and the most suitable design was chosen to be further analysed. The hollow design was chosen as it is unlikely to undergo warpage and requires a smaller amount of material thus lowering the cost of material and operation. D. M. Nuruzzaman et al. [8] studied the position of the gate and its effect on the flow of material. The parameter that was analysed is fill time, the temperature at flow front, the pressure at the end of fill, shear rate and warp. The result obtained was found to be reliable and can be used for the actual manufacturing process. Y. Shen et al. [9] studied the gate design for a thin walled injection moulding part. Parameters such as shear rate, the velocity of melt plastic, filling time and injection pressure were taken into account when selecting the suitable gate. The study found that the analysis using numerical simulation is excellent for the part, and the most suitable gate position is obtained.

An analysis to determine the most suitable gate location and injection parameters for a 25 tooth spur gear was accomplished in this research. The gear was designed using SolidWorks and the analysis was done using Autodesk Simulation Moldflow Advisor (ASMA). Each result was then compared to select the most suitable runner system for the spur gear.

\section{Methodology}

In this research, a spur gear will be designed using SolidWorks and then analysed using Autodesk Simulation Moldflow Analysis. By having this analysis, the injection moulding process of the gear can be optimized and suitable operating parameters can be obtained.

\subsection{Design of Spur Gear}

The gear was designed using SolidWorks according to the parameters shown in Table 1. The gear design can be seen in Figure 1. Three runner system were designed with each having a different gate location. For Design 1 and 2, the gate and runner are located at the centre and in Design 3 the gate and runner are on the body of the gear.

The runner system for each design can be seen in Table 2. The first design of the spur gear can be seen in Figure 2. This design has four runners and gate which is located in the centre. The size for runners are $3 \mathrm{~mm}$ and the gate is $6 \mathrm{~mm}$.

Table 1. Spur gear parameters.

\begin{tabular}{|c|c|}
\hline Parameter & Dimension \\
\hline Module & $2 \mathrm{~mm}$ \\
\hline Number of teeth & 25 \\
\hline Angle of tooth & 25 \\
\hline Face width & $15 \mathrm{~mm}$ \\
\hline
\end{tabular}

Table 2. Runner system parameter

\begin{tabular}{|c|c|c|c|c|}
\hline \multirow{2}{*}{ Design } & \multicolumn{4}{|c|}{ Runner System } \\
\cline { 2 - 3 } & $\begin{array}{c}\text { No. of } \\
\text { gates }\end{array}$ & $\begin{array}{c}\text { Gate } \\
\text { dimension }\end{array}$ & $\begin{array}{c}\text { Runner } \\
\text { dimension }\end{array}$ & $\begin{array}{c}\text { Sprue } \\
\text { dimension }\end{array}$ \\
\hline Design 1 & 4 & $3 \mathrm{~mm}$ & \multirow{2}{*}{$6 \mathrm{~mm}$} & \multirow{2}{*}{$8 \mathrm{~mm}$} \\
\hline Design 2 & 2 & $3 \mathrm{~mm}$ & \\
\hline Design 3 & 4 & $1 \mathrm{~mm}$ & & \\
\hline
\end{tabular}


The second design is shown in Figure 3. This design has two runners and gates with the same dimension as Design 1.

The third design has four runners and gate located on the face of the gear. The gate is a conical cylinder with the diameter at the gear face is $1 \mathrm{~mm}$ and at the runner end is $3 \mathrm{~mm}$. The runners are also in a conical cylinder shape with the diameter at the sprue end is $6 \mathrm{~mm}$. The design can be seen in Figure 4.

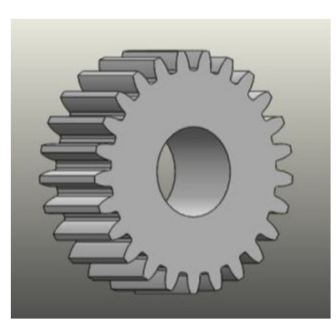

Fig. 1. Design of spur gear

\subsection{Gate Location Analysis}

This analysis was done to determine the most suitable position of the gate based on the design of the gear. The analysis will show the gating suitability and the flow resistance encountered by the material the design.

The result obtained from this analysis is the preliminary result, and the suggested gating position can be taken into consideration when setting up the runner system before the injection moulding analysis. In the analysis setting of ASMA, the gate location is chosen. The clarification for each result is obtained from the tutorial for ASMA [10].

Fig. 2. Design 1 of runner system on spur gear
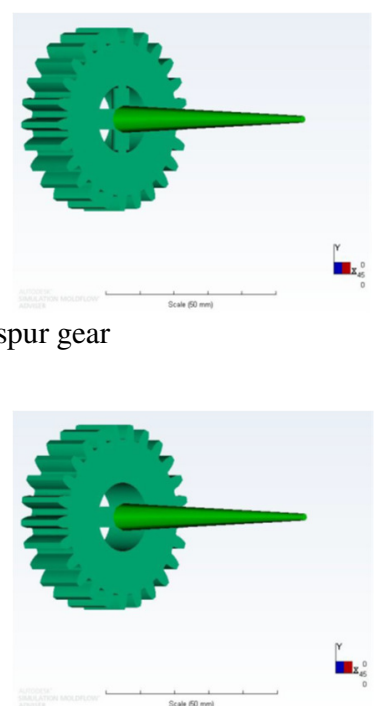

Fig. 3. Design 2 of runner system on spur gear 


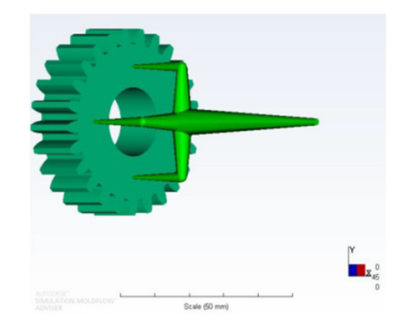

Fig. 4. Design 3 of runner system on spur gear

\subsection{Injection Moulding Analysis of Spur Gear}

The analysis selected for the simulation are Cooling Quality, Sink Mark, Fill + Pack and Wrap. The parameters of the injection process are shown in Table 3.

Table 3. Autodesk Simulation Moldflow Analysis parameters

\begin{tabular}{|c|c|}
\hline Parameter & Setting \\
\hline Material & $\begin{array}{c}\text { Generic Shrinkage Characterised } \\
\text { Material: Generic ABS }\end{array}$ \\
\hline Melting temperature & $230^{\circ} \mathrm{C}$ \\
\hline Mould Temperature & $60^{\circ} \mathrm{C}$ \\
\hline $\begin{array}{c}\text { Maximum Machine } \\
\text { Injection Pressure }\end{array}$ & $180 \mathrm{Mpa}$ \\
\hline
\end{tabular}

\section{Results and Discussion}

\subsection{Gate Location Analysis}

From the gate location analysis, two results were obtained which are flow resistance indicator and gating suitability. For Design 1 and 2, the runner and gate are included, since it is at the centre of the gear, making it a part of the gear. Meanwhile, for Design 3, it is not included, because the gate location is on the gear face.

Figure 5 shows the flow resistance on the front view. The blue region has the lowest resistance while the red region has the highest resistance. It can be noted that the low resistance regions are around the gate and at the tooth. This showed that the proposed position of gate and runner in Design 1 is acceptable.

Figure 5 also shows the gating suitability for Design 1. Blue indicates the best position while the red colour indicates the worst position to place a gate. It shows that the most suitable gate location is around the centre, which is our proposed position for Design 1.

Figure 6 shows the flow resistance for Design 2. The lowest resistance is at the centre while other positions have the intermediate resistance. The gating suitability for Design 2 is shown in the right. From the figure, the most suitable design of gate is near the centre.

Figure 7 shows the flow resistance of the material for Design 3. Most positions have low and intermediate resistance except at the tooth. This may be caused by the small cavity of the tooth and the initial flow of material which starts on the front face of the gear rather than at 
the centre. It also shows the suitable positions to place gates. It can be noted that the positions are around the face of the gear. The circles visible in Figure 7 are the proposed position of the gate for Design 3.
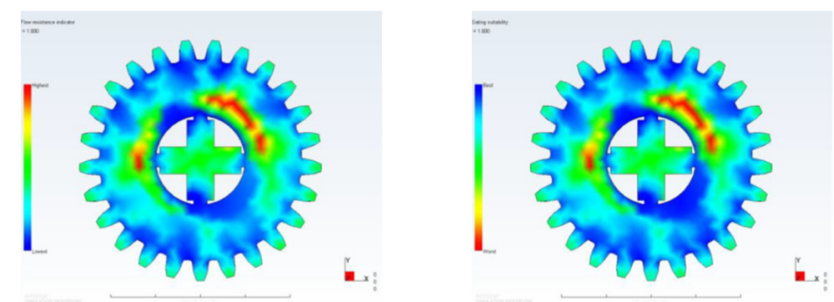

Fig. 5. Flow Resistance (left) and Gating Suitability (right) of Design 1
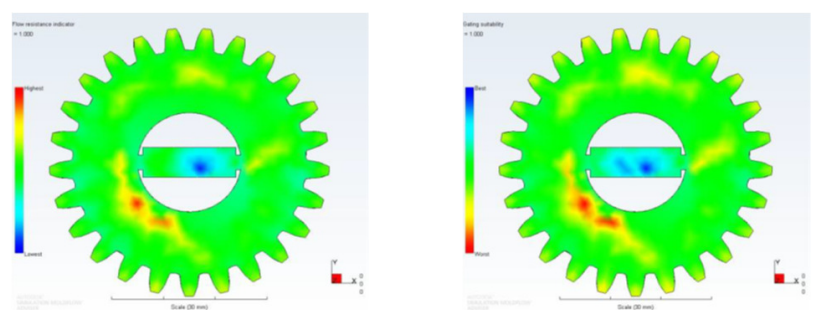

Fig. 6. Flow Resistance (left) and Gating Suitability (right) of Design 2.
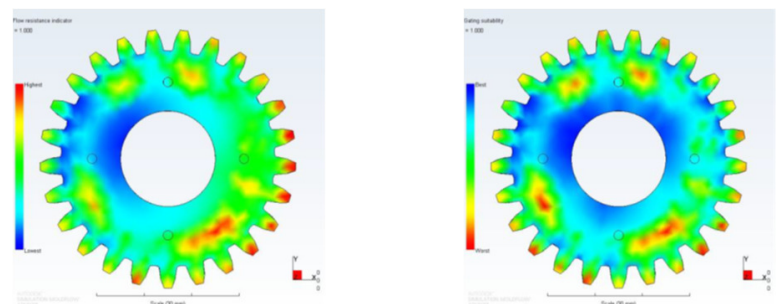

Fig. 7. Flow Resistance (left) and Gating Suitability (right) of Design 3.

\subsection{Autodesk Simulation Moldflow Analysis}

The position of runner system is placed based on the results obtained in the gate location analysis. The results obtained from the analysis according to the runner design will be discussed.

\subsubsection{Confidence of Fill}

The confidence of fill is the capability of the material to fill up the cavity. In this research, the cavity is in the shape of a spur gear. Figure 8 (left) shows that the fill for Design 1 is high. Almost all the cavities are filled with material and the air traps will be discussed later in the following results.

Design 2 and Design 3 also have a high confidence of fill. From the results, all the gate design is acceptable as every design have a high confidence of fill.

\subsubsection{Fill Time}


The fill time for Design 1 is 0.7591 second seen in Figure 8 (right). Design 2 have the longest fill time which is 1.196 second, meanwhile the fill time for Design 3 is the shortest at 0.448 second.

The fill time for each design affects the cycle time of injection process. Therefore, the shorter the time, the better the cycle time. However, other parameters should also be considered in deciding the gate location.
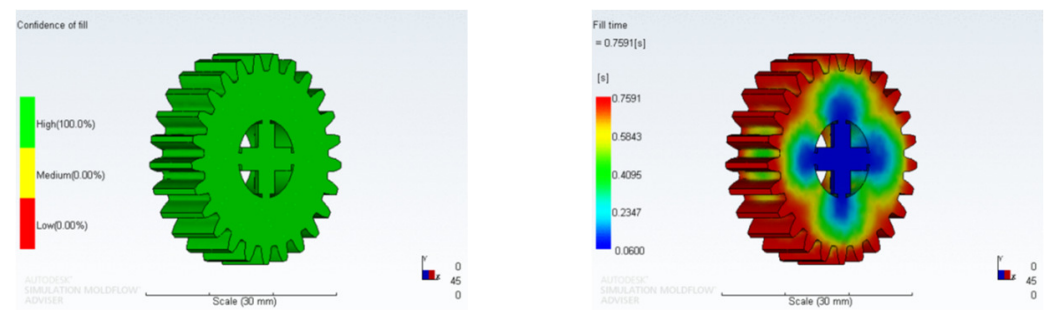

Fig. 8. Confidence of fill (left) and Fill time (right) for Design 1

\subsubsection{Air Traps}

Air traps are spaces in the cavity which is not filled with the injected material. Most of the air traps on Design 1,2 and 3 are in the tooth. This is expected as gear is a complex shape to be injected. The challenge is to reduce the air traps to as minimum as possible.

In Figure 9 (left), the air traps for Design 1 are only present at the end of the tooth. In Design 2, air traps are present at the tooth end and at the centre which can be seen in Figure 9 (right). This air trap position may be due to the gate location which is $180^{\circ}$ of each other. The material takes a longer time to fill the entire cavity as proven in the fill time results where Design 2 has the longest fill time. The air traps for Design 3 is almost identical to Design 1, where the air traps are present at the tooth end.
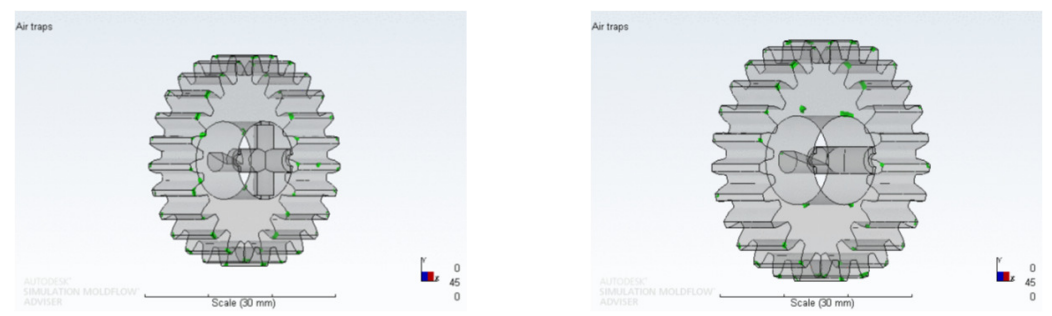

Fig. 9. Air traps in Design 1 (left) and Design 2 (right)

\subsubsection{Cooling Time Variance}

Cooling time variance is the amount of time taken for sections of the part to cool down compared to the average cooling time. The negative value indicates the time for solidifying is much shorter than the average time.

Design 1 takes the longest time for cooling which is 85.72 second as shown in Figure 10 (right). This is caused by the amount of gate present and its location. The thickness of the gear also affects the cooling time.

The cooling time for Design 2 and Design 3 are 85.03 second and 80.01 second respectively.

Design 3 has the shortest cooling time which is influenced by the gate location. The red region on Design 3, Figure 10 (right) is much smaller compared to the others. The gate 
location for Design 3 is around the red region, making it cool much faster. The tooth region cools much faster in Design 1 compared to other design.
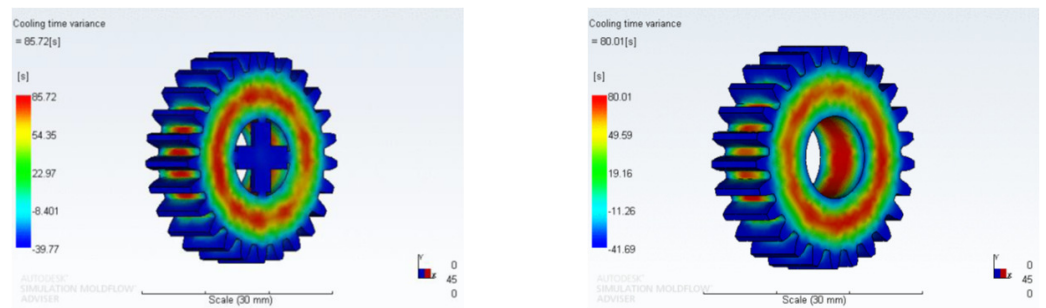

Fig. 6. Cooling time for Design 1 (left) and Design 3 (right)

\subsubsection{Time to Reach Ejection Temperature}

Time to reach ejection temperature is the time needed for the part to solidify enough so that it can be ejected from the mould.

The time for Design 1 to reach ejection temperature is 221.6 second shown in Figure 11 (left). The cooling time for the tooth and gate location are fast, while the body of the gear took the longest time. This is due to the thickness of the gear causing it to cool a lot slower.

Design 2 took the shortest time at 208 seconds, while the longest time was 223 second by Design 3 in Figure 11 (right). All the design had the longest cooling time at the body of the gear.
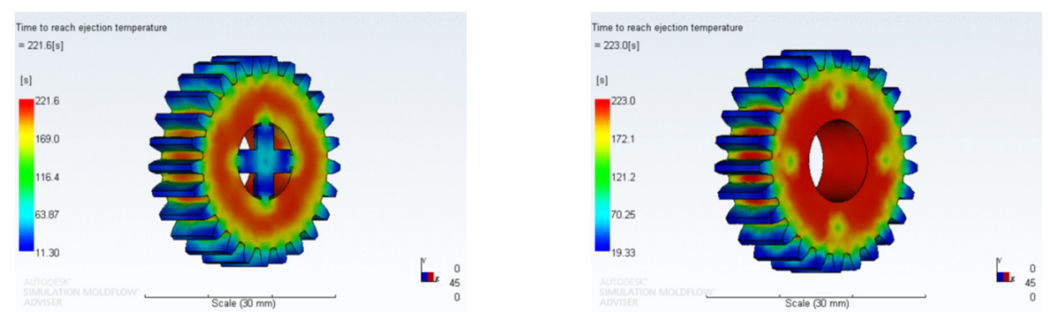

Fig. 11. Time to reach ejection temperature in Design 1 (left) and Design 3 (right)

\subsubsection{Average Temperature}

The average temperature shows the bulk temperature of the material when it is injected. The desired results are a consistent range of temperature throughout the cavity. This indicates that the material flows without any blockage. The consistent range of temperature also gives a better weld line and finishing of the product.

Design 1 has the most stable material temperature throughout the cavity which is seen in Figure 12. This can be obtained due to the amount of gate present and the location.

The average temperature on Design 2 is not stable due to the slow flow of material caused by the number gates and its opposite position. For Design 3, the gate position on the face of the gear did not help in stabilizing the material temperature throughout the cavity. 
Fig. 12. Average temperature of Design 1

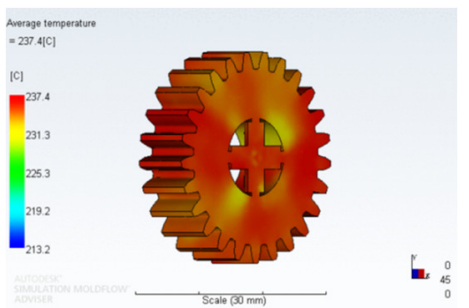

\subsubsection{Temperature at Flow Front}

This result shows the temperature of material when they reach a certain point in the cavity. To have a good flow of material into the cavity, the temperature flow front must be around $2-5^{\circ} \mathrm{C}$ of the processing temperature of the material used. Based on the results in Figure 13, the temperature of Design 1 is within the processing temperature of ABS which is at $230^{\circ} \mathrm{C}$. While for Design 2 and 3 the temperature is higher, which can lead to material degradation and surface defects.

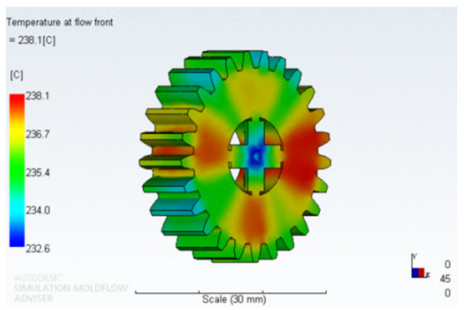

Fig. 13. Temperature at flow front for Design 1

\subsubsection{Quality Prediction}

This result predicts the quality of gear produced by using the proposed runner system. Design 1 and 2 have acceptable quality at the tooth region while the face has a medium quality as seen in Figure 14. The most important part of the gear is the tooth. Therefore, this result is acceptable. However, this is not the case in Design 3. Based on the simulation, the quality of injected part is bad, making the proposed runner system unsuitable for injecting gear.
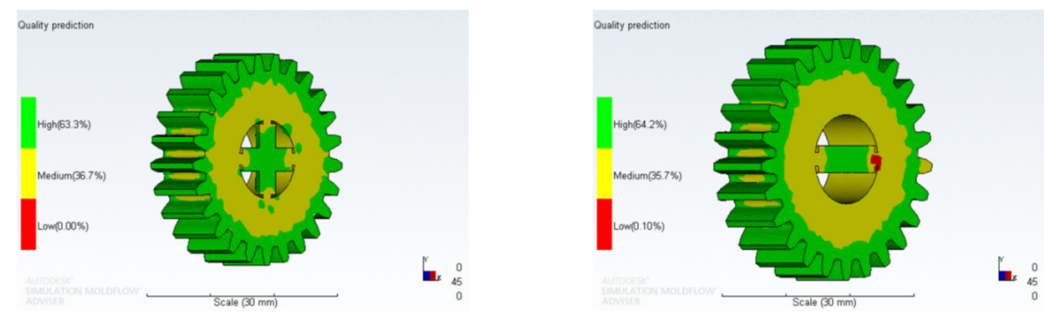

Fig. 14. Quality prediction of Design 1 (left) and Design 2 (right)

\subsubsection{Sink Mark Estimation}

Every proposed design has sink marks near the centre seen in Figure 15 left and right. This can be caused by the thick face width of the gear and the long-time taken for the centre to 
cool down, causing it to produce sink mark when it eventually cools down. Since the face of the gear is not critical, these results can be accepted.
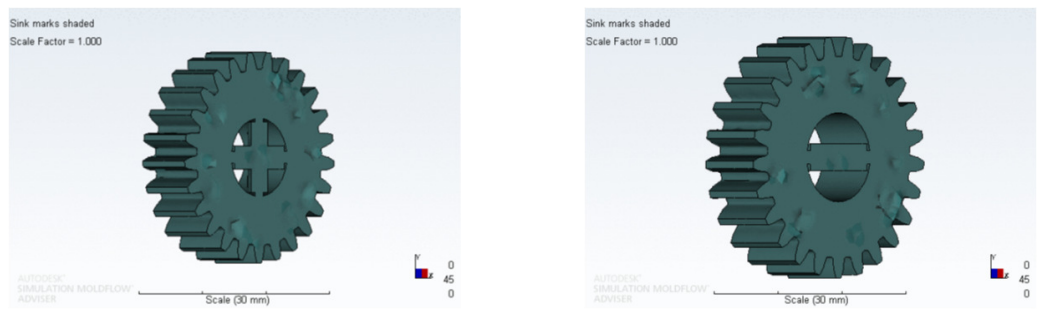

Fig. 15. Sink mark on Design 1 (left) and Design 2 (right)

\subsubsection{Volumetric Shrinkage}

Volumetric shrinkage is the percentage of each node shrinking based on the original part volume when it reaches ambient temperature $\left(25^{\circ} \mathrm{C}\right)$. Design 1 has the lowest percentage at 9.922\% followed by Design 2 at $9.313 \%$ and Design 3 at 10.44\%. Each design has the same shrinkage location as shown in Figure 16. Since the location does not affect the accuracy of the gear tooth, the shrinkage is acceptable.

Fig. 16. Volumetric shrinkage of Design 1

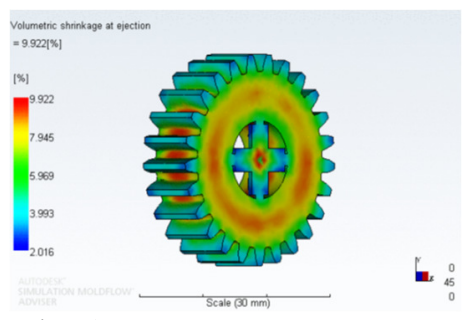

\subsubsection{Weld Lines}

Weld lines are the position where the molten material converges together. In Design 1 and 3, 4 weld lines were present seen in Figure 17. For Design 2, 2 weld line is present.
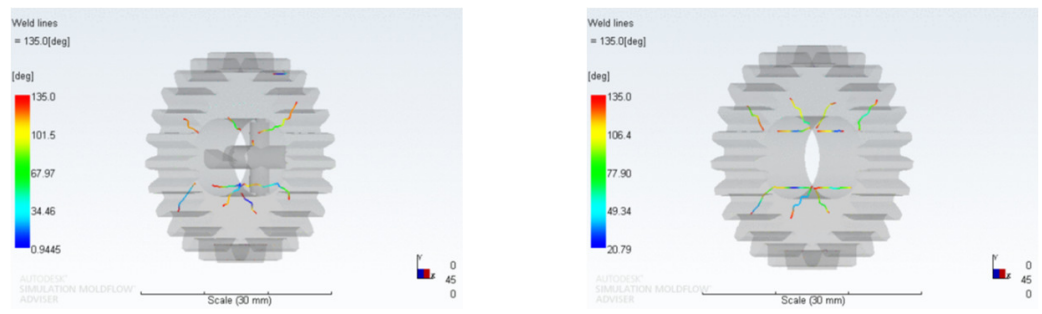

Fig. 17. Weld line on Design 1 (left) and Design 3 (right)

\subsubsection{Warpage Indicator}

Warpage indicator highlights the areas that are approaching or exceeding specified nominal deflection. In this analysis, all three designs have low deflections where the lowest deflection 
is in Design 1 at $2.573 \mathrm{~mm}$ seen in Figure 18. This is then followed by Design 2 at $2.604 \mathrm{~mm}$ and Design $32.713 \mathrm{~mm}$ seen.

Fig. 18. Warpage indicator in Design 1

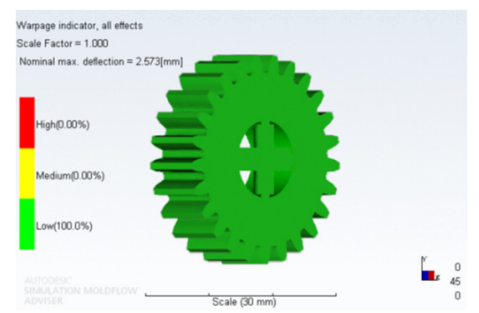

\section{Conclusion}

Based on the results, Design 1 gives a better average temperature, temperature flow front, injected product quality, volumetric shrinkage and warpage indication compared to the other design. For the fill time and cooling time Design 3 gave the best results. Design 2 had the shortest time to reach the ejection temperature.

The best runner system was Design 1 as it gives the most advantage compared to the other design. The design will then be used for manufacturing an injection moulding mould. The injected products will then be compared to the result obtained from the analysis to verify the data obtained and the software accuracy and capability.

The writers express their highest gratitude to Automotive Excellence Centre of Faculty of Mechanical Engineering, Universiti Malaysia Pahang for their support of this research through grant number RDU150386.

\section{References}

1. J. Vlachopoulos and D. Strutt, Mater. Sci. Technol. 19, p. 9, (2003)

2. C. D. Han, Rheology and Processing of Polymeric Materials: Volume 1: Polymer Rheology: (Oxford University Press, 2007)

3. C. D. Han, Rheology and Processing of Polymeric Materials: Volume 2: Polymer Processing (Oxford University Press, 2007)

4. A. Özdemir, O. Uluer, and A. Güldaş, Polym. Test., 23, p. 957-966, (2004)

5. E. Hakimian and A. B. Sulong, Mater. Design, 42, pp. 62-71, (2012)

6. B. Sha, S. Dimov, C. Griffiths, and M. S. Packianather, J. Mater. Process. Tech., 183, pp. 284-296, (2007)

7. W. A. Wan Abdul Rahman, L. T. Sin, and A. R. Rahmat, J. Mater. Process. Tech., 197, pp. 22-30, (2008)

8. D. M. Nuruzzaman, N. Kusaseh, S. Basri, A. N. Oumer, and Z. Hamedon, IOP Conference Series: Materials Science and Engineering, 114, (2016)

9. Y.-K. Shen, C.-W. Wu, Y.-F. Yu, and H.-W. Chung, Int. Commun. Heat Mass, 35, pp. 728-734, (2008)

10. "Autodesk Moldflow Communicator 2012, Fill analysis results," Revision 1 ed, (2012) 